\title{
Light triggered detection of aminophenyl phosphate with a quantum dot based enzyme electrode
}

\author{
Waqas Khalid', Gero Göbel², Dominik Hühn', Jose-Maria Montenegro', Pilar Rivera-Gill', Fred Lisdat ${ }^{2}$ and \\ Wolfgang J Parak ${ }^{1 *}$
}

\begin{abstract}
An electrochemical sensor for $p$-aminophenyl phosphate (pAPP) is reported. It is based on the electrochemical conversion of 4-aminophenol (4AP) at a quantum dot (QD) modified electrode under illumination. Without illumination no electron transfer and thus no oxidation of 4AP can occur. pAPP as substrate is converted by the enzyme alkaline phosphatase (ALP) to generate 4AP as a product. The QDs are coupled via 1,4-benzenedithiol (BDT) linkage to the surface of a gold electrode and thus allow potential-controlled photocurrent generation. The photocurrent is modified by the enzyme reaction providing access to the substrate detection. In order to develop a photobioelectrochemical sensor the enzyme is immobilized on top of the photo-switchable layer of the QDs. Immobilization of ALP is required for the potential possibility of spatially resolved measurements. Geometries with immobilized ALP are compared versus having the ALP in solution. Data indicate that functional immobilization with layer-by-layer assembly is possible. Enzymatic activity of ALP and thus the photocurrent can be described by Michaelis- Menten kinetics. pAPP is detected as proof of principle investigation within the range of $25 \mu \mathrm{M}-1 \mathrm{mM}$.
\end{abstract}

\section{Introduction}

Colloidal quantum dots (QDs), which are fluorescent semiconductor nanoparticles, have recently brought impact to various disciplines, as has been highlighted in various review articles [1-5]. QDs have been recently discussed also as new building blocks for the construction of electrochemical sensors [6-12]. Upon optical illumination (below the wavelength of the first exciton peak QDs have a a continuous absorption spectrum, with a local maximum at the exciton peak [13]) electron hole pairs are generated inside QDs. Due to these charge carriers electrons can be transferred to or from the QDs. QDs thus can be oxidized/reduced and can serve as light-controlled redox active element and can be integrated in electrochemical signal chains [9,14-16]. The key advantage hereby is that the redox reaction of the QD surface can be virtually switched on and off by light. QD have been also used as elements of signal transduction of enzymatic reactions $[17,18]$.

\footnotetext{
* Correspondence: wolfgang.parak@physik.uni-marburg.de

${ }^{1}$ Fachbereich Physik and WZMW, Philipps Universität Marburg, Germany Full list of author information is available at the end of the article
}

In the present work we wanted to apply QDs as lightcontrolled redox active element for the enzymatic detection of $p$-aminophenyl phosphate ( $p \mathrm{APP}$ ) with alkaline phosphatase (ALP). ALP is a widely used enzyme in bioanalysis as it has a high turnover rate and broad substrate specificity [19]. The enzyme is particularly interesting as label for immunoassays [20,21]. Very sensitive substrate recycling schemes have been also reported $[22,23]$. Four different groups of substrates are known for ALP: i) ßglycerophosphate and hexose phosphate [24-26], ii) phenyl phosphate $[27,28]$ and $ß$-naphthyl phosphate [29], iii) $p$-nitrophenyl phosphate [30] and phenolphthalein diphosphate [31,32], 4-methyl-umbellipheryl phosphate [33] and $p$-aminophenyl phosphate ( $p$ APP) [34], and iv) phosphoenol pyruvate [35]. Electrochemical detection has been reported for a number of ALP substrates $[36,37]$, in particular for phenyl phosphate. However, $p$ APP is claimed to be a better substrate for ALP than phenyl phosphate, as its product 4-aminophenol (4AP) is more easily oxidizable than phenol, which is the product of phenyl phosphate, as it does not foul the electrode even at higher concentrations, and as it has a rather
Ciomed Central

C 2011 Khalid et al; licensee BioMed Central Ltd. This is an Open Access article distributed under the terms of the Creative Commons Attribution License (http://creativecommons.org/licenses/by/2.0), which permits unrestricted use, distribution, and reproduction in any medium, provided the original work is properly cited. 
reversible electrochemical behavior [34]. For this reason we chose $p$ APP as substrate in the present study. Readout of the enzymatic reaction was performed with the QDmodified electrode [6]. We hereby put particular interest in the way of immobilization of ALP on the electrode. In previous work the enzymes were suspended in the solution above the sensor electrode [6,9]. Here we go a step further and directly immobilize the enzyme on the QDmodified electrode. This was done in order to investigate whether a specific enzymatic reaction can be coupled with a photoinitiated reaction at a QD modified electrode in a way that the recognition element is integrated with the transducer. The potential advantage of light-triggered detection would be the possibility of spatially resolved detection [38-41]. Only at the illuminated parts of the electrode a photocurrent signal is induced. By having different enzymes immobilized at different regions of the electrode they could be selectively addressed by illumination. Thus, two key elements of this study are the following. First, instead of using enzymes in solution as in previous studies we demonstrate that enzymatic reactions can also be followed when enzymes are immobilized on the sensor surface, which is a requirement for potential spatially resolved analysis. Second, we investigate how the way of immobilization influences the sensing properties.

\section{Materials and Methods}

Materials: CdS QDs were grown via thermal decomposition of precursors under the presence of organic surfactant molecules following published procedures [42]. 1,4benzenedithiol (BDT) was purchased from TCI Europe, Belgium. Chloroform, toluene, methanol, acetone, ethanol, sodium sulfide (nanohydrate), alkaline phosphatase (from bovine intestinal mucosa type VII S), 4-nitrophenyl phosphate disodium hexahydrate, 4-aminophenol (4AP), phosphate buffer, sodium poly(styrene sulfonate) (PSS, $\left.\mathrm{M}_{\mathrm{w}}=56,000\right)$, poly(allylamine hydrochloride) (PAH, $\left.\mathrm{M}_{\mathrm{w}}=70,000\right)$, and potassium ferri/ferro cyanide were purchased from Sigma Aldrich and used without further purification. All aqueous solutions were prepared using $18 \mathrm{M} \Omega$ ultra purified water. The electrochemical measurement cells and electronics have been described in a previous publication [43] and comprised a home built potentiostat, an $\mathrm{Ag} / \mathrm{AgCl}$ reference electrode (\#MF 2078 RE-6 from BASi, UK), and a lock-in amplifier (EG\&G Princeton Applied Research model \# 5210). Illumination was done with a xenon lamp (PTI model A1010 arc lamp housing, UXL-75XE Xenon Lamp from USHIO, powered by PTI LPS-220) modulated by an optical chopper (Scitec instruments).

Immobilization of QDs: CdS QDs were immobilized on top of gold electrodes following a previously published protocol [43], cfg. Figure 1. First, the gold electrodes (Au film evaporated on glass chips) were cleaned by sonication toluene for five minutes. For cleaning the cyclic voltammetry $(\mathrm{CV})$ of the gold electrode was performed in $1 \mathrm{M} \mathrm{NaOH}$ for 20 minutes within the potential limits of $-0.8 \mathrm{~V}<\mathrm{U}<+0.2 \mathrm{~V}$, and later in $0.5 \mathrm{M} \mathrm{H}_{2} \mathrm{SO}_{4}$ for 30 minutes within the potential limits of $-0.2 \mathrm{~V}<\mathrm{U}<1.6 \mathrm{~V}$ (the $\mathrm{CV}$ curves are shown in Additional File 1). After cleaning, the gold electrodes were placed in a solution of $50 \mathrm{mM}$ BDT dissolved in toluene for 24 hours. This resulted in a self assembled monolayer of BDT on the gold surface due to formation of thiol-gold bonds. In the next step CdS QDs dissolved in toluene (typically with a first exciton peak around $380 \mathrm{~nm}$, concentration around $140 \mu \mathrm{M}$ ) were spin coated at a speed of $6000 \mathrm{rpm}$ on top of the BDT coated gold electrodes. After spin coating the gold electrodes were rinsed twice with toluene to remove the excess of QDs.

Confirmation of QDs immobilization: Immobilization of CdS QDs on top of the Au electrodes was performed with current measurements. CVs were recorded before and after immobilization of BDT and QDs on top of gold electrodes with $\mathrm{Fe}^{3+} / \mathrm{Fe}^{2+}$ as redox couple in solution [43]. While on bare gold electrodes the typical oxidation and reduction currents could be observed these were not visible in the case of gold electrodes coated with BDT and QDs (see Additional File 1 for data). Alternatively current at fixed bias voltage was recorded for gold electrodes before and after immobilization of BDT and QDs, while illumination was switched on and off. In the case of QDs present on top of the Au electrode a photocurrent could be measured under illumination (date are shown in Additional File 1)

Solubilized versus immobilized enzymes: In order to observe the enzymatic reaction of ALP and $p$ APP the enzyme ALP was either directly added to the bath solution (S) or immobilized on top of the QDs layer (I). All geometries are depicted in Figure 2. In the simplest case $\left(S_{0}\right)$ the Au electrodes with spin coated QDs layer were directly used without further modification. For the next geometry $\left(\mathrm{S}_{1}\right)$ a polyelectrolyte layer of PAH was coated on top of the CdS QDs layer mediated by electrostatic attraction by immersing the QDs coated Au electrode in a solution of PAH for 5 minutes $(0.02 \mathrm{M}$ monomer concentration, $\mathrm{pH}=6.5,0.5 \mathrm{M} \mathrm{NaCl})[43,44]$. Unbound excess $\mathrm{PAH}$ was removed by rinsing. $\mathrm{PAH}$ is positively charged. We speculate that the QDs layer is not tight so that PAH is attracted by the negatively charged underlying BDT monolayer. Stability after rinsing confirmed stable deposition of PAH. To this configuration a second polyelectrolyte layer $\left(\mathrm{S}_{2}\right)$ of PSS could be added by immersing the PAH coated QDs-Au electrode $\left(\mathrm{S}_{1}\right)$ for 5 minutes in a solution of PSS $(0.02 \mathrm{M}$ monomer concentration, $\mathrm{pH}=6.5,0.5 \mathrm{M} \mathrm{NaCl}$ ), followed by a rinsing 


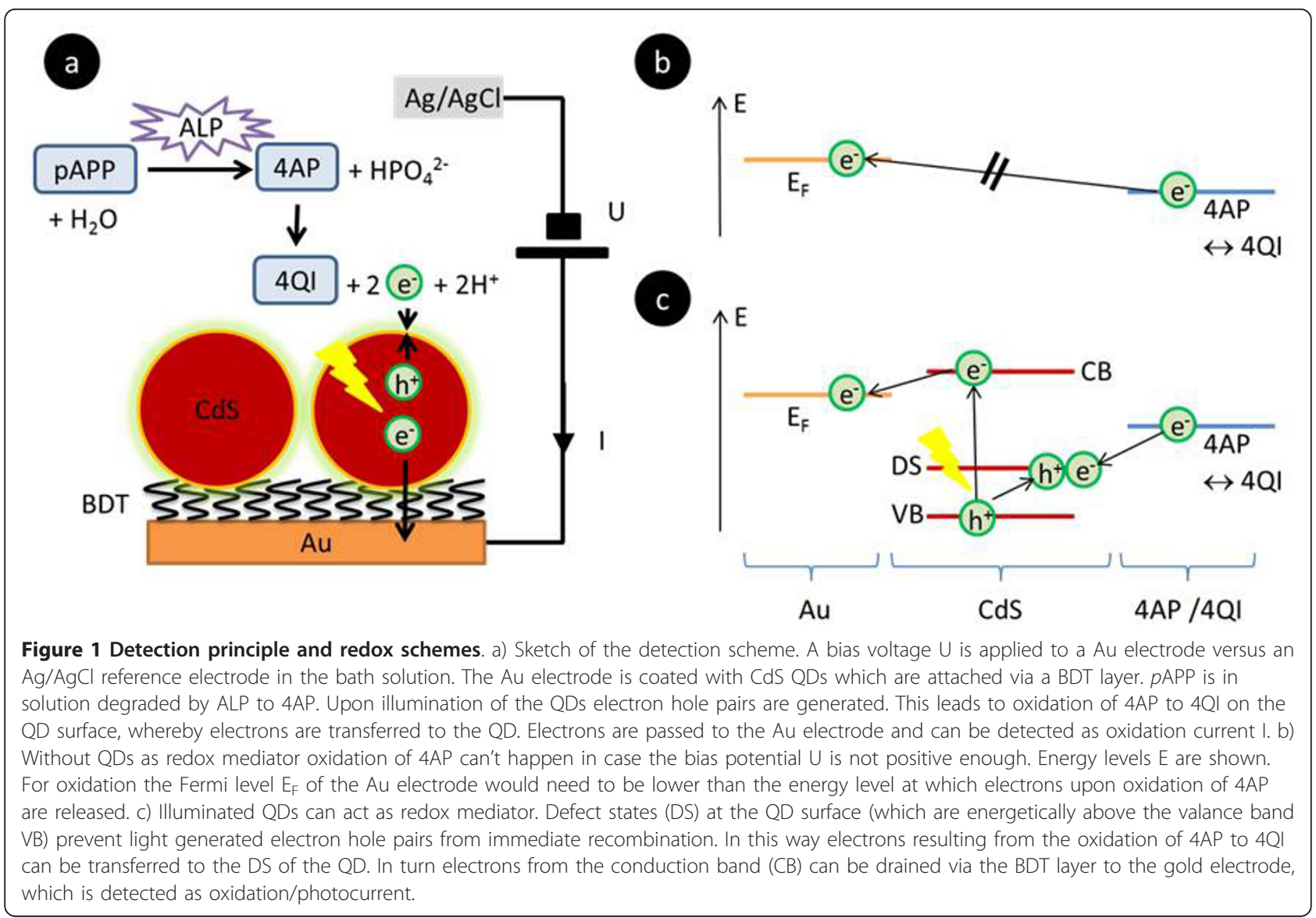

step to remove unbound PSS. PSS is negatively charged and thus electrostatically attracted by the PAH layer [44]. In all three geometries $\left(\mathrm{S}_{0}, \mathrm{~S}_{1}, \mathrm{~S}_{2}\right)$ ALP was added directly to the solution on top of the electrode without any direct attachment. We also tried to directly immobilize ALP on the electrodes. For this purpose QDs coated $\mathrm{Au}$ electrodes were first modified with a PAH layer, leading to a positively charged surface $\left(S_{1}\right)$. To this negatively charged ALP $[45,46]$ was added by 5 minutes immersion in a solution of ALP (120 units $/ \mathrm{ml}, \mathrm{pH}=$ 7.8, $10 \mathrm{mM}$ phosphate buffer). Attachment of ALP to $\mathrm{PAH}$ was mediated by electrostatic interaction $\left(\mathrm{I}_{1}\right)$. In order to increase the amount of immobilized ALP, the coating procedure was repeated $\left(\mathrm{I}_{2}\right)$. The electrodes with one layer of ALP were immersed again for 5 minutes in a solution of $\mathrm{PAH}$, followed by rinsing, and then for 5 minutes in a solution of ALP followed by rinsing. This step-wise multilayer assembly mediated by electrostatic interaction [44] lead to two layers of ALP on top of the QD coated Au electrodes. Layer-by-layer assembly was confirmed with fluorescence labeled polyelectrolytes (data see Additional File 1).

Electrochemical measurements of dose-response curves: A constant bias voltage $U$ was applied and the base line photocurrent $\mathrm{I}_{0}$ was measured in phosphate buffer solution ( $\mathrm{pH} 7.8$ ) by switching illumination on and off with mechanical shutter, see Figure 3 . Then the electrochemical cell was rinsed twice and a known amount of 4AP (product of ALP) or $p$ APP (substrate for ALP) was added and the photocurrent I was measured again. Also hereby illumination was switched on and off several times with a mechanical shutter. For the next measurement the cell was again rinsed twice, an increasing amount of $4 \mathrm{AP}$ or $p \mathrm{APP}$ was added, and the photocurrent I was measured while switching on and off the illumination. With this procedure the response in photocurrent $\Delta \mathrm{I}(\mathrm{c})=\mathrm{I}(\mathrm{c})-\mathrm{I}_{0}$ to different concentrations of $4 \mathrm{AP}$ or $p \mathrm{APP}$ was determined, see Figure 3 . The resulting dose-response curves are plotted in Figures 45. It has to be noted that after each excitation there is a slight decrease in photocurrent, which we have previously ascribed to degradation of the QDs layer [43]. Polyelectrolyte layers above the QDs layer have been demonstrated to increase stability [43].

\section{Results and Discussion}

Detection of 4AP and sensor principle: First we have investigated whether the CdS modified gold electrode 


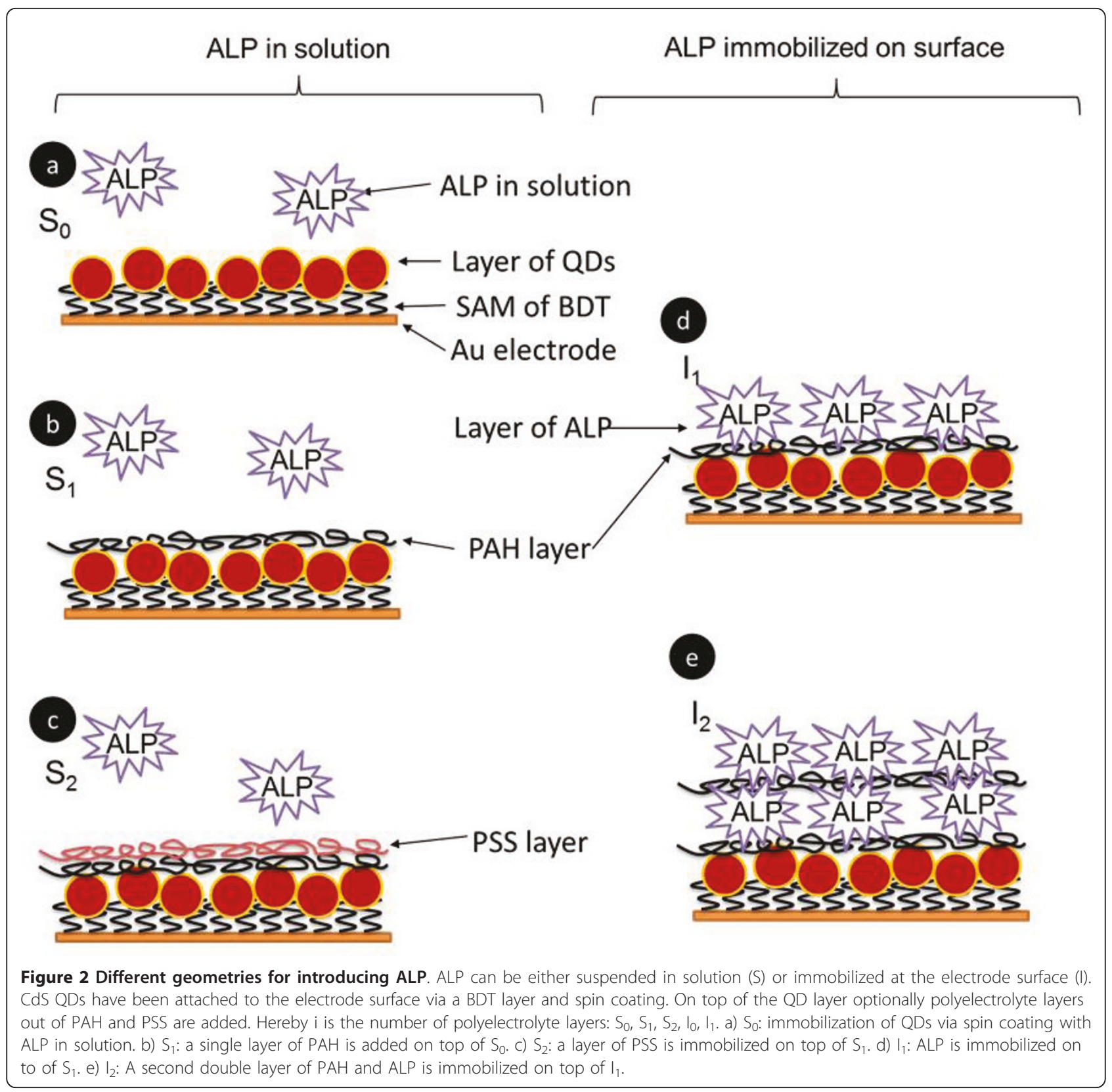

can be used as transducer to the analysis of 4AP - the reaction product of ALP reaction. For this purpose the electrode potential $U$ was varied and the current I was measured under pulsed illumination. A clear response of the photocurrent to the presence of 4AP was found indicating that the QDs electrode provides a suitable surface for 4AP oxidation (cfg. Figure 3). Since the electrochemical behavior of $4 \mathrm{AP}$ is well known, the reaction is shown in Figure 6.

A maximum of photocurrent was detected for an applied bias potential of $+200 \mathrm{mV}$ against $\mathrm{Ag} / \mathrm{AgCl}, 3 \mathrm{M}$ KCL (data are shown in Additional File 1). For this reason all following measurements were performed at fixed bias $\mathrm{U}=+200 \mathrm{mV}$. On the basis of the sensitivity of the QD electrode for 4AP, we wanted to construct a photoelectrochemical sensor. A sketch of our sensor concept is depicted in Figure 1. In presence of ALP $p \mathrm{APP}$ is hydrolyzed to $4 \mathrm{AP}$ and $\mathrm{HPO}_{4}{ }^{2-}$ (cfg. Figure 7) which is subsequently converted at the electrode under illumination.

The actual sensor electrode was composed out of QDs which were coupled via a 1,4-benzenedithiol (BDT) layer on top of a gold film electrode. A bias voltage $\mathrm{U}=$ $+200 \mathrm{mV}$ was applied and the corresponding current I 


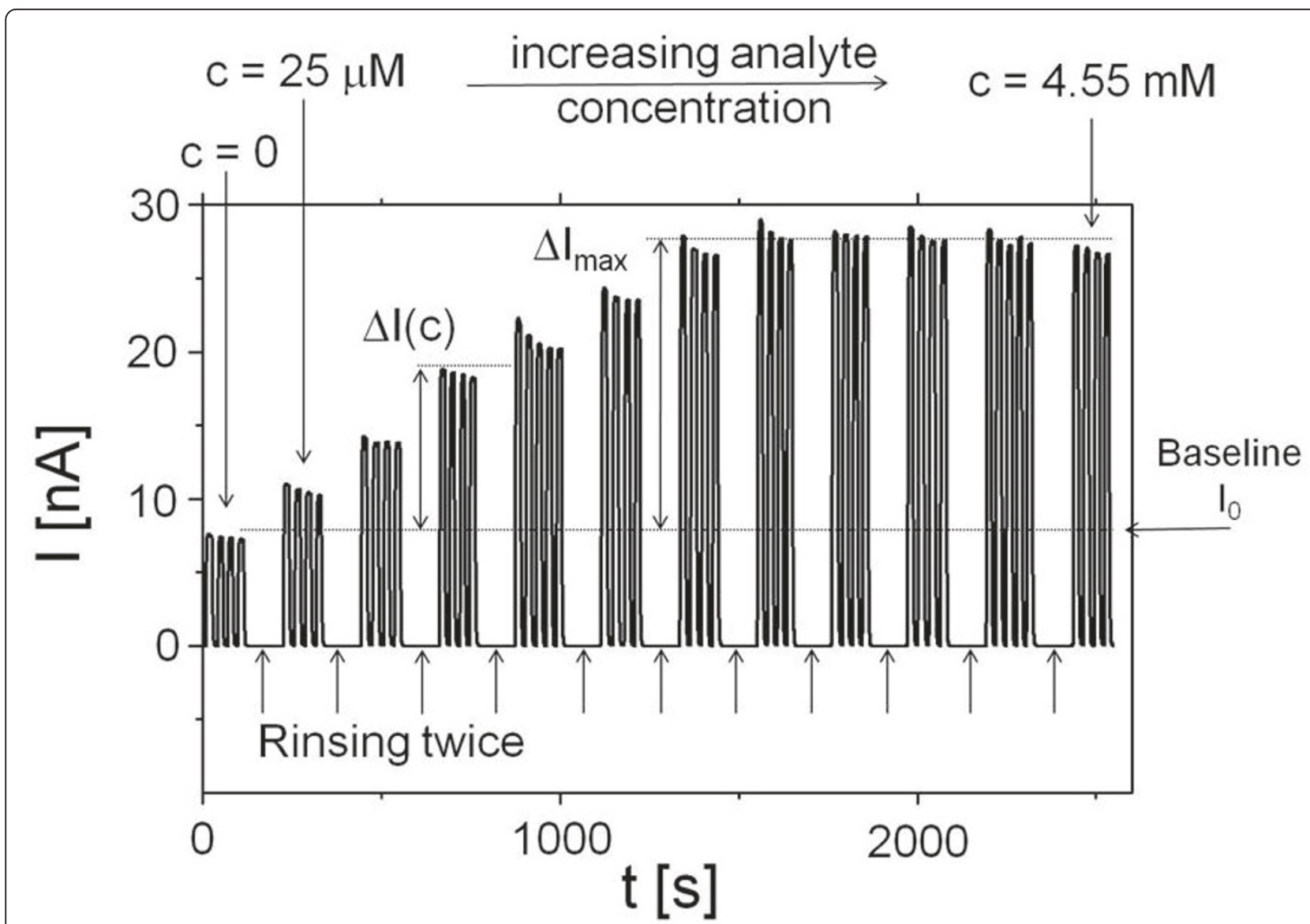

Figure 3 Detection principle of dose response curves. A constant bias $U=+200 \mathrm{mV}$ is applied and current I is detected. Hereby illumination is switched on and off with a shutter. During the periods without illumination no current can flow. The base line current $I_{0}$ is detected. After 2 rinsing steps analyte is added (in this case 4AP dissolved in $25 \%$ methanol and $75 \%$ phosphate buffer at pH 5, geometry $\mathrm{S}_{0}$ ) and the respective photocurrent I is recorded in phosphate buffer with final $\mathrm{pH}=7.8$. This process is repeated while successively adding more analyte (in the present example 4AP concentration was increased from $25 \mu \mathrm{M}$ to $4.55 \mathrm{mM}$ ). The respective oxidation current response $\Delta I(\mathrm{c})$ for each analyte concentration $\mathrm{c}$ is derived by subtracting the base line $\mathrm{I}_{0}$ from the detected photocurrent $\mathrm{I}(\mathrm{c})$. The dose response curve for the present example is displayed in Figure 4a.

was recorded. Upon illumination of the QDs, electronhole pairs were generated. Electron transfer could take place in between CdS QDs and the 4AP/QI - redox couple in solution and in between the QDs and the electrode. Thus, the QDs could be used as a light-triggered interlayer to transfer electrons from the redox couple, present in solution to the electrode. The energetical situation of the electron transfer pathway is depicted in Figure 1b/c. 4AP could be only oxidized to $4 \mathrm{QI}$ if the two released electrons could be transferred to an energetically lower level. In case the bias $\mathrm{U}$ applied to a gold electrode was not positive enough (i.e. its Fermi level was above the energy of the $4 \mathrm{AP} / 4 \mathrm{QI}$ redox couple), no oxidation of 4AP could occur (cfg. Figure 1b). However, if at the same bias illuminated QDs were used oxidation of 4AP was possible (cfg. Figure 1c). Upon illumination, electrons in the QDs were excited from the valence band $(\mathrm{VB})$ to the conduction band $(\mathrm{CB})$, resulting in electrons $\left(\mathrm{e}^{-}\right)$and holes $\left(\mathrm{h}^{+}\right)$. The holes were trapped in defect states (DS) [47] at the surface of the QDs. 4AP could now be oxidized to $4 \mathrm{QI}$ upon transferring the electrons to the QDs where they recombined with the holes. In turn, electrons were transferred from the $\mathrm{CB}$ of the QDs to the gold electrode, thus creating an oxidation current I.

In order to realize this signal chain in a sensor format (with the potential possibility of spatially resolved detection) the enzyme needed to be immobilized on the photosensitive electrode. The layer by layer approach in depositing protein molecules is a very favorable technique since it allows control on the deposited amount in one layer but also in the whole assembly by the number of deposition steps $[48,49]$. In order to deposit ALP, the positively charged polyelectrolyte PAH was used here. 


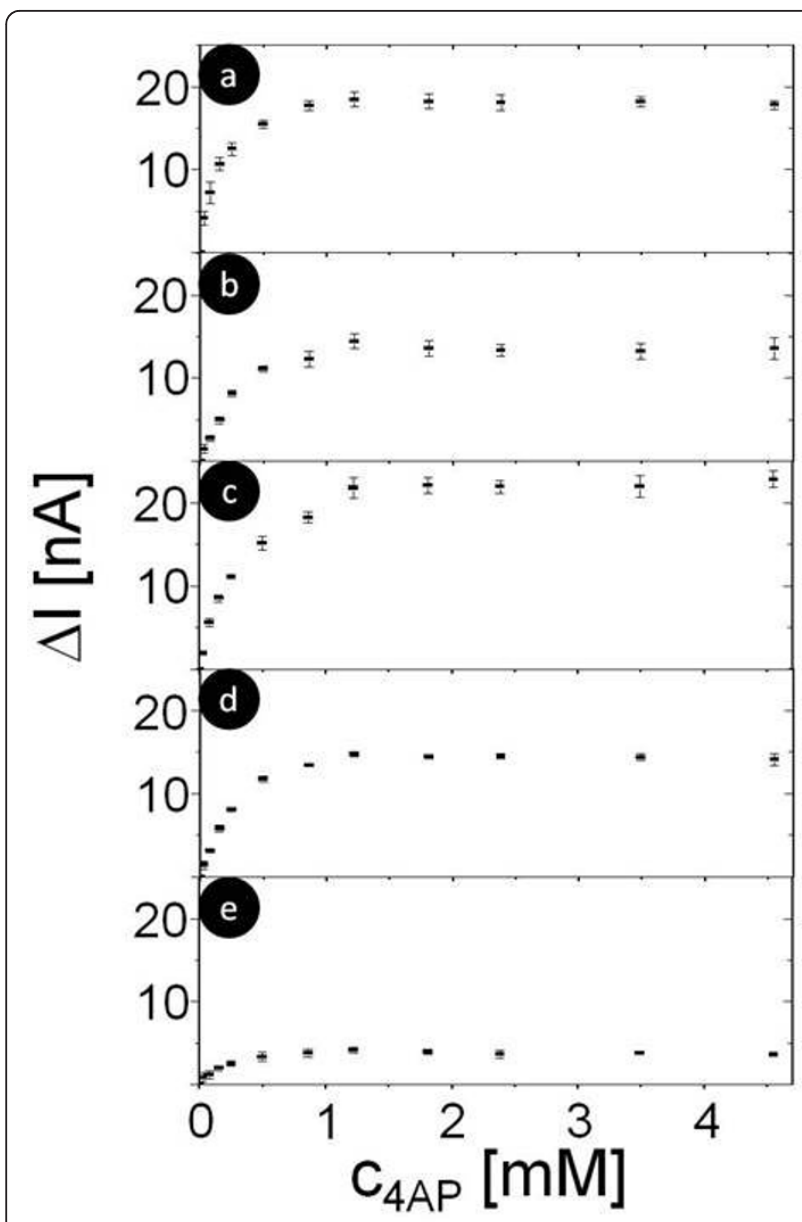

Figure 4 Dose response curve for detection of 4AP (originally dissolved in $25 \%$ methanol and $75 \%$ phosphate buffer $\mathrm{pH} 5$ ) as recorded in phosphate buffer $\mathrm{pH} 7.8$ at bias potential of +200 $\mathrm{mV}$ for geometries a) $S_{0}$, b) $S_{1}$, c) $S_{2}$, d) $I_{1}$, e) $I_{2}$. The resulting photocurrent $\mathrm{I}$ is plotted versus the concentration $\mathrm{C}$ of $4 \mathrm{AP}$.

We have investigated ALP as a monolayer but also as bilayer. In order to mimic the influence of the charge situation we have studied the effect of the polyelectrolyte alone on the sensing behavior. Figure 2 summarizes the different systems which have been analyzed on the way to a sensing electrode. To ensure high sensitivity for 4AP detection, the influence of protein and polyelectrolyte interlayers on the photocatalytic oxidation of 4AP were investigated. The oxidation current for different 4AP concentrations was determined for all 5 geometries shown in Figure 2. For each geometry a dose response curve was generated, see Figure 4. Data demonstrate that the concentration of $4 \mathrm{AP}$ can be reasonably detected within the ranges of $25 \mu \mathrm{M}$ to around $1.5 \mathrm{mM}$. For 4AP concentrations larger than $1.5 \mathrm{mM}$ the photocurrent response is saturated for all geometries. However, there was a significant difference in the maximum response of the oxidation current. The

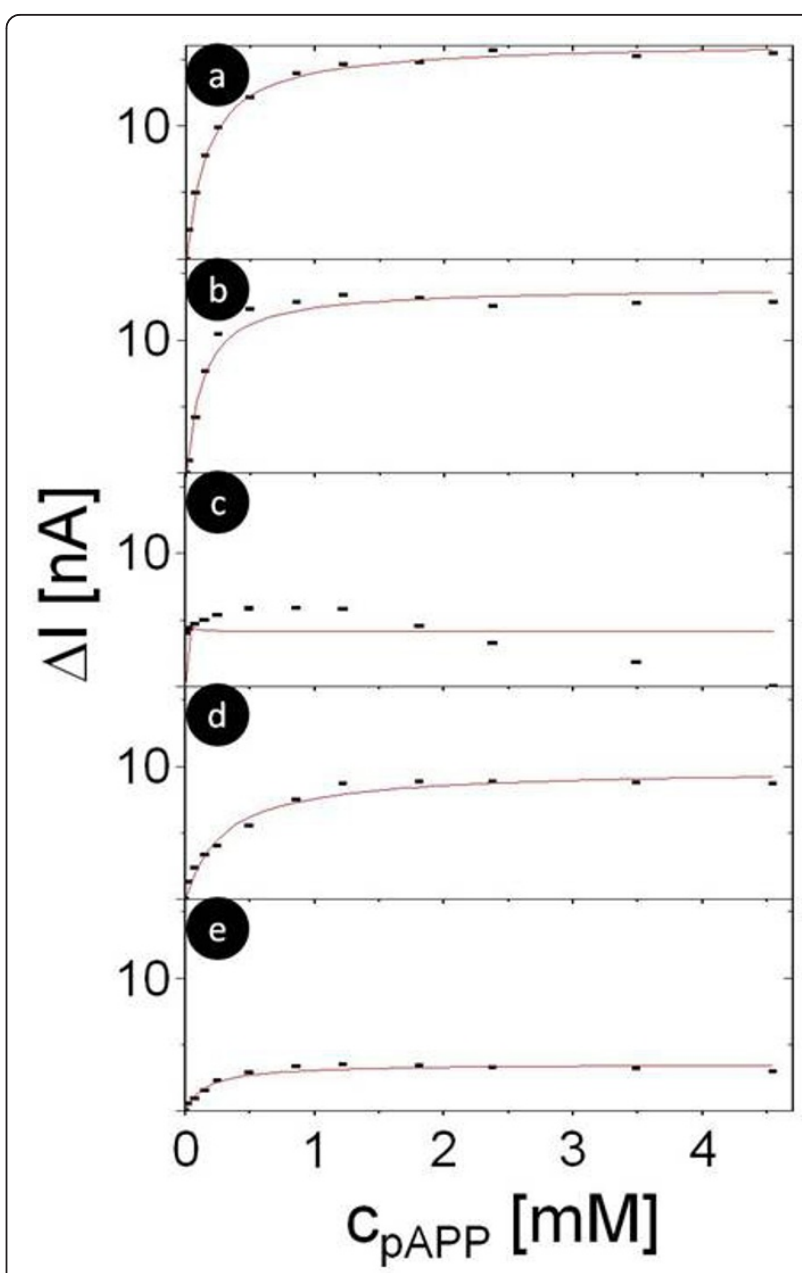

Figure 5 Dose response curve for detection of pAPP as recorded in phosphate buffer $\mathrm{pH} 7.8$ at bias potential of +200 $\mathrm{mV}$ under the presence of ALP (120 units per $2 \mathrm{ml}$ in case of geometry S) for geometries a) $S_{0}$, b) $S_{1}$, c) $S_{2}$, d) $I_{1}$, e) $I_{2}$. The resulting photocurrent $I$ is plotted versus the concentration $\mathrm{c}$ of pAPP. The solid line in each of the curves indicates a fit with the Michaelis-Menten equation. Values are displayed in Table 1

maximum photocurrents $\Delta \mathrm{I}_{\max }$ at saturation are displayed in Table 1. For geometry $\mathrm{S}_{2}$ the higher current probably might be due to electrostatic attraction of negatively charged PSS and 4AP. For geometry $\mathrm{I}_{2}$ the photocurrent response is smaller than for the other geometries (Figure 4e). This might be ascribed to a rather dense assembly of ALP with PAH hindering 4AP to reach the QDs modified electrode. At any rate, the data show that the polyelectrolyte used and the immobilized protein still allow the conversion of the reaction product of ALP. Thus another important precondition for the sensor construction seems to be fulfilled.

Detection of $p$-aminophenyl phosphate: As an experimental complication it has to be pointed out that $p \mathrm{APP}$ has limited stability, since $p$ APP decomposes slowly in 


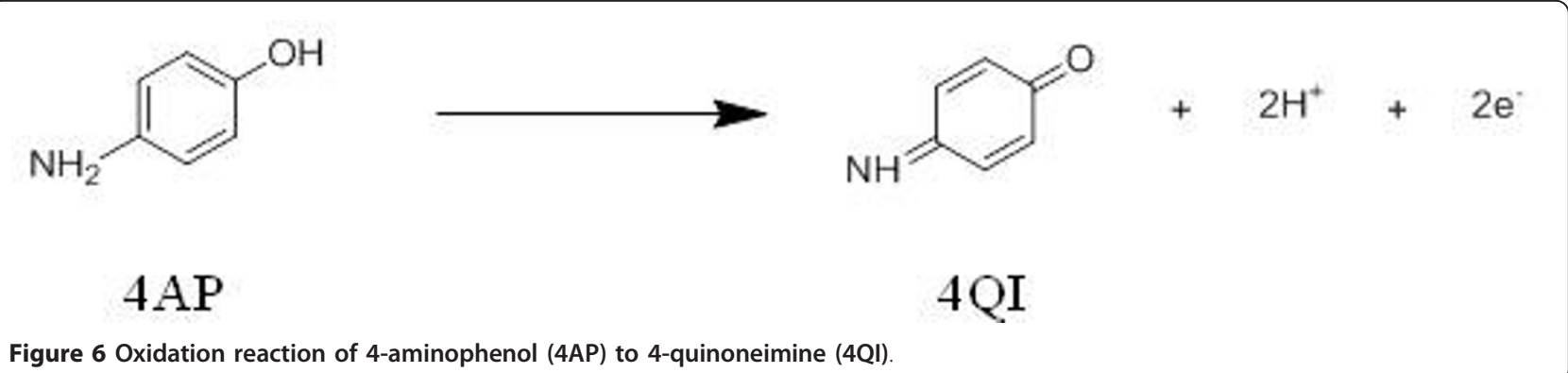

alkaline solution [50]. In order to be sure to test the enzyme activity on the CdS electrode, $p$ APP has also been investigated with the 3 different geometries given in Figure 2 (without the enzyme). Only a very small response of about 1-2 $\mathrm{nA}$ was obtained (cfg. Table 1 and Additional File 1). This is an order of magnitude lower than the response to 4AP and ensured specific detection of the substrate $p$ APP by the enzymatic conversion as will be shown in the following. In a first step, the enzymatic reaction of ALP with $p$ APP causing the production of 4AP was investigated with the enzyme in solution. As has been shown above this is possible, as there is response of the photocurrent to the product $4 \mathrm{AP}$, but barely to the substrate $p$ APP. As shown in Figure 5 a-c the enzymatic reaction could be detected for all the 3 geometries in which the enzyme was free in solution, as indicated in Figure 2. However, there were significant differences in the response curves. In contrast to the detection of $4 \mathrm{AP}$ alone (geometry $\mathrm{S}_{0}$ ) the response in geometry $\mathrm{S}_{2}$ for $p \mathrm{APP}$ in the conversion with ALP is small, probably due to a depletion of the substrate near the electrode because of electrostatic repulsion.

In a final step the enzyme has been immobilized in a single and double layer as depicted in Figure $2 \mathrm{~d}$ and $2 \mathrm{e}$. By this method, the biospecific recognition element is part of the device and no substances have to be added to the solution despite the molecule to be detected (here $p \mathrm{APP})$. In the case of geometry $\mathrm{I}_{2}$ the maximum photocurrent response is relatively low (Figure 5e). This corresponds directly to the control experiments in which 4AP has been detected directly (Figure 4e). The ALP/polyelectrolyte layers seem to hinder diffusion of 4AP to the QDs surface. Immobilization of ALP also reduces the steepness of the dose-response curve ( $c f$. Figure 5a,b versus Figure 5d). Nevertheless, for electrodes with a single layer of ALP fixed with the polyelectrolyte PAH a very well defined response to the enzyme substrate is obtained. This shows that the concept of a photobioelectrochemical sensor can be realized with the example of ALP. Sensitivity for 4AP detection could be provided in the range from $25 \mu \mathrm{M}$ to $1.5 \mathrm{mM}$ ( $c f$. Figure 3 , in all geometries shown, addition of $25 \mu \mathrm{M}$ clearly triggered a response in the photocurrent). We want to point out that the aim of this paper was not the development for a practical sensor for direct $p$ APP detection in real samples, but rather to demonstrate the proof of concept for a photo-triggered enzyme sensor (of the first generation). In order to further analyze the response behavior quantitatively, the dose response curves were fitted with the Michaelis-Menten equation, cfg. Eq. 1 [51]. Hereby we assumed that the rate of the enzymatic reaction $\mathrm{v}$ was proportional to the oxidation current $\mathrm{I}$, and thus $\mathrm{v} / \mathrm{v}_{\max }=\Delta \mathrm{I} / \Delta \mathrm{I}_{\max }$, whereby $\mathrm{v}_{\max }$ is the maximum reaction rate and $\mathrm{K}_{\mathrm{M}}$ is the MichaelisMenten constant, $c f$. Eq. 1. Values are given in Table 1.

$$
\Delta \mathrm{I} / \Delta \mathrm{I}_{\max }=\mathrm{c}(p \mathrm{APP}) /\left(\mathrm{K}_{\mathrm{M}}+\mathrm{c}(p \mathrm{APP})\right)
$$

In literature $\mathrm{K}_{\mathrm{M}}$ values of $0.48 \mathrm{mM}$ [52] and 0.056 $\mathrm{mM}$ [53] have been reported, which are in the same<smiles>Nc1ccc(O[Se](=O)(O)c2ccc(N)cc2)cc1</smiles> 
Table 1 Oxidation currents for the different geometries

\begin{tabular}{ccccc}
\hline Geometry & $\Delta_{\max }[\mathrm{nA}]$ direct detection of $4 \mathrm{AP}$ & $\boldsymbol{\Delta l}_{\max }[\mathrm{nA}]$ direct detection of $p A P P$ & $\Delta \mathrm{I}_{\max }[\mathrm{nA}]$ enzymatic reaction & $\mathrm{K}_{\mathbf{M}}[\mathrm{mM}]$ \\
\hline $\mathrm{S}_{0}$ & 18.4 & 2.1 & 16.3 & 0.16 \\
\hline $\mathrm{S}_{1}$ & 14.4 & 2.1 & - & 0.12 \\
\hline $\mathrm{S}_{2}$ & 21.8 & - & 9.8 & - \\
\hline $\mathrm{I}_{1}$ & 14.8 & - & 3.5 & 0.29 \\
\hline $\mathrm{I}_{2}$ & 4.1 & - & 0.15 \\
\hline
\end{tabular}

Maximum oxidation currents are recorded for different geometries $\mathrm{S}_{0}, \mathrm{~S}_{1}, \mathrm{~S}_{2}, \mathrm{I}_{1}, \mathrm{I}_{2}$ as recorded in phosphate buffer with pH = 7.8. Data are shown for detection of 4AP (cfg. Figure 4), pAPP (cfg. Additional File 1), and detection of 4AP after enzymatic degradation of pAPP with ALP (cfg. Figure 5). In the case of the enzymatic reaction also the Michaelis-Menten constant $\mathrm{K}_{\mathrm{M}}$ is given.

order of magnitude as the values detected in our work with the enzyme in solution. For the sensor configuration developed $\left(I_{1}\right)$ a larger value can be derived from the experiments. It has to be pointed out that in the case of the polyelectrolyte -fixed enzyme the $K_{M}$ value has to be considered as apparent $K_{M}$ value since here the concentration of half maximum conversion rate is influenced by the immobilization [54]. Comparison of the $\Delta \mathrm{I}_{\max }$ values as obtained for direct detection of $4 \mathrm{AP}$ (Figure 4) and detection of 4AP after enzymatic degradation of $p$ APP to 4 AP shows that both oxidation signals (detected at the same geometry and provided abundance of enzyme) are quite similar. This is in good agreement with the detection principle proposed.

In summary the developed sensor as illustrated in Figure $2 \mathrm{~d}$ by immobilizing the ALP via the polyelectrolyte $\mathrm{PAH}$, provides the proof of principle for a detection system for the enzyme substrate $p$ APP. The analytical performance with a detection regime within the concentration range from 0.025 to $1 \mathrm{mM}$ is relatively poor, so that the here presented device has to be seen as a proof of principle demonstrator rather than as an applicable sensor.

\section{Conclusions}

A light controlled bioelectrochemical sensor for $p$ APP has been demonstrated. By using QDs as interlayer on gold, 4AP could be oxidized and thus detected via a corresponding photocurrent in case the QDs were illuminated. Enzymes could be functionally immobilized on the sensor surface. This provides the basis for future spatially resolved measurements [40] by selectively illuminating and reading-out only the area of interest of an electrode which is non-structured, but modified with different immobilized enzyme systems. The approach presented here allows for observing enzymatic reactions which yield $4 \mathrm{AP}$ as product. We have demonstrated this for the substrate $p$ APP and the enzyme ALP. A crucial point for such measurements is to ensure high local enzyme concentration and specificity for the detection of the enzymatic product. By using a polyelectrolyte layer of PAH, the enzyme ALP could be immobilized on the electrode surface, retaining enzymatic activity. However, polyelectrolyte layers can also hinder diffusion of the molecule to be detected 4AP to the QD surface, thus hindering detection. For this reason permeability of the polyelectrolyte layers has been studied here for the respective molecule.

\section{Additional material}

Additional file 1: Supporting information: Cleaning of gold

electrodes. Immobilization of QDs on the electrode surface.

Confirmation of QDs immobilization. Detection of 4-aminophenol and $p$ aminophenyl phosphate (pAPP). Immobilization of ALP in polyelectrolyte

layers on top of the QDs layer. Set-up for the detection of fotocurrents [55-57].

\section{Acknowledgements}

This work was supported by the German Research Foundation (DFG, grants PA 794/3-1, L1706/2-1).

\section{Author details}

${ }^{1}$ Fachbereich Physik and WZMW, Philipps Universität Marburg, Germany. ${ }^{2}$ Biosystems Technology, University of Applied Sciences Wildau, Wildau, Germany.

\section{Authors' contributions}

WK, GG, DH and JMM: performed experiments and analyzed data. PRG: designed experiments and analyzed data. FL and WJP: designed experiments and wrote manuscript. All authors read and approved the final manuscript.

\section{Competing interests}

The authors declare that they have no competing interests.

Received: 18 August 2011 Accepted: 7 October 2011

Published: 7 October 2011

\section{References}

1. Wang C, Gao X, Su XG: In vitro and in vivo imaging with quantum dots. Analytical And Bioanalytical Chemistry 2010, 397:1397-1415.

2. Pinaud F, Clarke S, Sittner A, Dahan M: Probing cellular events, one quantum dot at a time. Nature Methods 2010, 7:275-285.

3. Resch-Genger U, Grabolle M, Cavaliere-Jaricot S, Nitschke R, Nann T: Quantum dots versus organic dyes as fluorescent labels. Nat Meth 2008 $5: 763$.

4. Zhang F, Ali Z, Amin F, Riedinger A, Parak WJ: In vitro and intracellular sensing by using the photoluminescence of quantum dots. Analytical And Bioanalytical Chemistry 2010, 397:935-942.

5. Parak WJ, Pellegrino T, Plank C: Labelling of cells with quantum dots. Nanotechnology 2005, 16:R5-R25. 
6. Stoll C, Kudera S, J.Parak W, Lisdat F: Quantum Dots on Gold:Electrodes For Photoswitchable Cytochrome c Electrochemistry. SMALL 2006, 2:741-743

7. Katz E, Zayats M, Willner I, Lisdat F: Controlling the direction of photocurrents by means of $\mathrm{CdS}$ nanoparticles and cytochrome cmediated biocatalytic cascades. Chemical Communications 2006, 1395-1397.

8. Stoll C, Gehring C, Schubert K, Zanella M, Parak WJ, Lisdata F: Photoelectrochemical signal chain based on quantum dots on goldSensitive to superoxide radicals in solution. Biosensors and Bioelectronics 2008, 24:260-265.

9. Schubert K, Khalid W, Yue Z, Parak WJ, Lisdat F: Quantum-Dot-Modified Electrode in Combination with NADH-Dependent Dehydrogenase Reactions for Substrate Analysis. Langmuir 2010, 26:1395-1400.

10. Liu Q, Lu XB, Li J, Yao X, Li JH: Direct electrochemistry of glucose oxidase and electrochemical biosensing of glucose on quantum dots/carbon nanotubes electrodes. Biosensors \& Bioelectronics 2007, 22:3203-3209.

11. Wang Z, Xu Q, Wang HQ, Yang Q, Yu JH, Zhao YD: Hydrogen peroxide biosensor based on direct electron transfer of horseradish peroxidase with vapor deposited quantum dots. Sensors And Actuators B-Chemical 2009, 138:278-282

12. Tang $L H$, Zhu YH, Yang XL, Sun JJ, Li CZ: Self-assembled CNTs/CdS/ dehydrogenase hybrid-based amperometric biosensor triggered by photovoltaic effect. Biosensors \& Bioelectronics 2008, 24:319-323.

13. Bawendi MG, Steigerwald ML, Brus LE: The quantum mechanics of large semiconductor clusters ("quantum dots"). Annu Rev Phys Chem 1990, 41:477-496.

14. Kucur E, Riegler J, Urban GA, Nann T: Determination of quantum confinement in CdSe nanocrystals by cyclic voltammetry. Journal of Chemical Physics 2003, 119:2333-2337.

15. Ehlert O, Tiwari A, Nann T: Quantum confinement of the thermodynamic functions for the formation of electrons and holes in CdSe nanocrystals. Journal Of Applied Physics 2006, 100.

16. Kucur E, Bucking W, Arenz S, Giernoth R, Nann T: Heterogeneous charge transfer of colloidal nanocrystals in ionic liquids. Chemphyschem 2006 , 7:77-81

17. Niemeyer CM: Functional hybrid devices of proteins and inorganic nanoparticles. ANGEW CHEM INT EDIT 2003, 42:5796-5800.

18. Willner I, Basnar B, Willner B: Nanoparticle-enzyme hybrid systems for nanobiotechnology. Febs Journal 2007, 274:302-309.

19. Bagel O, Limoges B, Schollhorn B, Degrand C: Subfemtomolar determination of alkaline phosphatase at a disposable screen-printed electrode modified with a perfluorosulfonated ionomer film. Analytical Chemistry 1997, 69:4688-4694.

20. Nistor C, Emneus J: An enzyme flow immunoassay using alkaline phosphatase as the label and a tyrosinase biosensor as the label detector. Analytical Communications 1998, 35:417-419.

21. Kreuzer MP, O'Sullivan CK, Guilbault GG: Alkaline phosphatase as a label for immunoassay using amperometric detection with a variety of substrates and an optimal buffer system. Analytica Chimica Acta 1999, 393:95-102.

22. Campas M, Olteanu MG, Marty JL: Enzymatic recycling for signal amplification: Improving microcystin detection with biosensors. Sensors And Actuators B-Chemical 2008, 129:263-267.

23. Wollenberger U, Schubert F, Scheller FW: Biosensor For Sensitive Phosphate Detection. Sensors And Actuators B-Chemical 1992, 7:412-415.

24. Bodansky A: Phosphatase studies II. Determination of serum phosphatase. Factors influencing the accuracy of the determination. Journal Of Biological Chemistry 1933, 101:93-104.

25. Shinowara GY, Jones $L M$, Reinhart $H L$ : The estimation of serum inorganic phosphate and " acid" and " alkaline" phosphatase activity. Journal of Biological Chemistry 1942, 142:921-933.

26. Tietz NW, Green A: Automated Procedure For Determination Of Phosphorus + Alkaline Phosphatase (Bodansky) In Serum. Clinica Chimica Acta 1964, 9:392-\&

27. Kind PRN, King EJ: Estimation Of Plasma Phosphatase By Determination Of Hydrolysed Phenol With Amino-Antipyrine. Journal Of Clinical Pathology 1954, 7:322-326.

28. King EJ, Armstrong AR: A convenient method for determining serum and bile phosphatase activity. Canadian Medical Association Journal 1934, 31:376-381.
29. Seligman AM, Chauncey HH, Nachlas MM, Manheimer LH, Ravin HA: The Colorimetric Determination Of Phosphatases In Human Serum. Journal of Biological Chemistry 1951, 190:7-15.

30. Bessey OA, Lowry OH, Brock MJ: A Method For The Rapid Determination Of Alkaline Phosphatase With 5 Cubic Millimeters Of Serum. Journal Of Biological Chemistry 1946, 164:321-329.

31. Fischl J, Segal S, Rabiah S: Microdetermination Of Phosphatases Employing Phenolphthalein Diphosphate As Substrate. Clinical Chemistry 1967, 13:941.

32. Huggins C, Talalay P: Sodium Phenolphthalein Phosphate As A Substrate For Phosphatase Tests. Journal Of Biological Chemistry 1945, 159:399-410.

33. Fernley HN, Walker PG: Kinetic Behaviour Of Calf-Intestinal Alkaline Phosphatase With 4-Methylumbelliferyl Phosphate. Biochemical Journal 1965, 97:95.

34. Tang HT, Lunte CE, Halsall HB, Heineman WR: P-Aminophenyl Phosphate An Improved Substrate For Electrochemical Enzyme-Immunoassay. Analytica Chimica Acta 1988, 214:187-195.

35. Fischer F, Siebert G: Optischer Test Zur Bestimmung Der Alkalischen Phosphate Im Serum. Klinische Wochenschrift 1961, 39:202.

36. McNeil CJ, Higgins IJ, Bannister JV: Amperometric Determination Of Alkaline-Phosphatase Activity - Application To Enzyme-Immunoassay. Biosensors 1987, 3:199-209.

37. Wehmeyer KR, Halsall HB, Heineman WR, Volle CP, Chen IW: Competitive Heterogeneous Enzyme-Immunoassay For Digoxin With Electrochemical Detection. Analytical Chemistry 1986, 58:135-139.

38. McConnell HM, Owicki JC, Parce JW, Miller DL, Baxter GT, Wada HG, Pitchford S: The Cytosensor Microphysiometer: Biological Applications of Silicon Technology. Science 1992, 257:1906-1912.

39. Licht S, Myung N, Sun Y: A Light Addressable Photoelectrochemical Cyanide Sensor. Analytical Chemistry 1996, 68:954-959.

40. Parak WJ, Hofmann UG, Gaub HE, Owicki JC: Lateral Resolution of Light Addressable Potentiometric Sensors: An Experimental and Theoretical Investigation. Sensors and Actuators A 1997, 63:47-57.

41. George M, Parak WJ, Gerhardt I, Moritz W, Kaesen F, Geiger H, Eisele I, Gaub HE: Investigation of the spatial resolution of the light-addressable potentiometric sensor (LAPS). Sensors and Actuators A 2000, 83:149-249.

42. Kudera S, Carbone L, Casula MF, Cingolani R, Falqui A, Snoeck E, Parak WJ, Manna L: Selective growth of PbSe on one or both tips of colloidal semiconductor nanorods. Nanoletters 2005, 5:445-449.

43. Yue Z, Khalid W, Zanella M, Abbasi AZ, Pfreundt A, Rivera_Gil P, Schubert K, Lisdat F, Parak WJ: Evaluation of quantum dots applied as switchable layer in a light-controlled electrochemical sensor. Analytical and Bioanalytical Chemistry 2010, 396:1095-1103.

44. Decher G: Fuzzy nanoassemblies: Toward Layered Polymeric Multicomposites. Science 1997, 277:1232-1237.

45. Latner AL, Parsons ME, Skillen AW: Isoelectric Focusing Of Human Liver Alkaline Phosphatase. Biochemical Journal 1970, 118:299.

46. Xie $\mathrm{Q}$, Alpers $\mathrm{DH}$ : The two isozymes of rat intestinal alkaline phosphatase are products of two distinct genes. Physiological Genomics 2000, 3:1-8.

47. Wuister SF, Donega CD, Meijerink A: Influence of thiol capping on the exciton luminescence and decay kinetics of $\mathrm{CdTe}$ and $\mathrm{CdSe}$ quantum. Journal of Physical Chemistry B 2004, 108:17393-17397.

48. Decher G, Schlenoff J: Multilayer Thin Films: Sequential Assembly of Nanocomposite Materials Wiley VCH; 2002.

49. Lisdat F, Dronov R, Mohwald H, Scheller FW, Kurth DG: Self-assembly of electro-active protein architectures on electrodes for the construction of biomimetic signal chains. Chemical Communications 2009, 274-283.

50. Gil EP, Tang HT, Halsall HB, Heineman WR, Misiego AS: Competitive Heterogeneous Enzyme-Immunoassay For Theophylline By FlowInjection Analysis With Electrochemical Detection Of Para-Aminophenol. Clinical Chemistry 1990, 36:662-665.

51. Hommes FA: Integrated Michaelis-Menten Equation. Archives of Biochemistry And Biophysics 1962, 96:28.

52. Gehring AG, Brewster JD, Irwin PL, Tu SI, Van Houten LJ: 1-Naphthyl phosphate as an enzymatic substrate for enzyme-linked immunomagnetic electrochemistry. Journal Of Electroanalytical Chemistry 1999, 469:27-33.

53. Thompson RQ, Barone GC, Halsall HB, Heineman WR: Comparison of Methods For Following Alkaline-Phosphatase Catalysis Spectrophotometric Versus Amperometric Detection. Analytical Biochemistry 1991, 192:90-95. 
54. Neugebauer S, Stoica L, Guschin D, Schuhmann W: Redox-amplified biosensors based on selective modification of nanopore electrode structures with enzymes entrapped within electrodeposition paints. Microchimica Acta 2008, 163:33-40.

55. Bauer CG, Eremenko AV, EhrentreichForster E, Bier FF, Makower A

Halsall HB, Heineman WR, Scheller FW: Zeptomole-detecting biosensor for alkaline phosphatase in an electrochemical immunoassay for 2,4dichlorophenoxyacetic acid. Analytical Chemistry 1996, 68:2453-2458.

56. Frew JE, Foulds NC, Wilshere JM, Forrow NJ, Green MJ: Measurement Of Alkaline-Phosphatase Activity By Electrochemical Detection Of Phosphate-Esters - Application To Amperometric Enzyme-Immunoassay. Journal Of Electroanalytical Chemistry 1989, 266:309-316.

57. Neumann H, Vanvreed M: An Improved Alkaline Phosphatase

Determination With P-Nitrophenyl Phosphate. Clinica Chimica Acta 1967, 17:183-187.

doi:10.1186/1477-3155-9-46

Cite this article as: Khalid et al:: Light triggered detection of aminophenyl phosphate with a quantum dot based enzyme electrode. Journal of Nanobiotechnology 2011 9:46.

\section{Submit your next manuscript to BioMed Central} and take full advantage of:

- Convenient online submission

- Thorough peer review

- No space constraints or color figure charges

- Immediate publication on acceptance

- Inclusion in PubMed, CAS, Scopus and Google Scholar

- Research which is freely available for redistribution

Submit your manuscript at www.biomedcentral.com/submit 